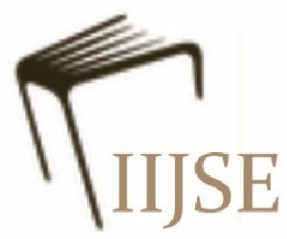

\title{
PENGARUH CELEBRITY ENDORSE ZAKAT TERHADAP MOTIVASI BERZAKAT DI YOGYAKARTA
}

\author{
Subur Subiyanto ${ }^{1}$ \\ Universitas Islam Indonesia \\ subursubianto@gmail.com
}

\begin{abstract}
Abstrak
Kata kunci:

Zakat, Celebrity

Endorse,

Motivasi

Berzakat

Indonesia sebagai negara berpenduduk mayoritas muslim memiliki potensi zakat luar biasa. Setiap tahun perolehan zakat Indonesia meningkat drastis, tentunya banyak hal yang dilakukan oleh lembaga zakat untuk menarik muzakki dalam membayar zakat, seperti beriklan dengan menggunakan pablik figur. Penelitian ini bertujuan untuk mengetahui pengaruh celebrity endorse zakat terhadap motivasi berzakat. Penyusun melakukan penelitian dengan pendekatan kuantitatif. Teknik pengambilan sampel dengan metode judgement sampling. Sampel dalam penelitian ini adalah para muzakki yang pernah berzakat di Dompet Dhuafa di Yogyakarta. Penengolahan data menggunakan regresi linear sederhana dengan program SPSS. Berdasarkan hasil analisis data diperoleh kesimpulan bahwa variable Celebrity Endorse berpengaruh positif dan signifikan terhadap Motivasi Berzakat. Hal ini dilihat dari nilai t hitung sebesar 2,648 dengan sig. $t$ sebesar 0,009 $(p<0,05)$.
\end{abstract}

\begin{abstract}
Indonesia as a predominantly Muslim country has tremendous zakat potential. Every year, the acquisition of zakat in Indonesia increases drastically. Of course many things have been done by zakat institutions to attract muzakki in paying zakat, such as advertising by using public figures. This study aims to determine the effect of zakat endorse celebrity on the motivation of tithe. The authors conducted the research by quantitative approach. The sampling technique was by judgment sampling method. The sample in this study was the muzakki who ever tithe at Dompet Dhuafa in Yogyakarta. Simple linear regression with SPSS program was used in data processing. Based on the results of data analysis, it is concluded that the Celebrity Endorse variable has a positive and significant effect on the motivation of tithe. It can be seen from the value of T-test of 2.648 with sig. $t$ of $0.009(p<0.05)$.
\end{abstract}

Keyword:

Zaqah, Celebrity

Endorse, Zaqah

Motivation 


\section{A. Pendahuluan}

Zakat sebagai rukun Islam ketiga, merupakan instrumen utama dalam ajaran Islam yang berfungsi sebagai distributor aliran kekayaan dari tangan "yang mampu" ketangan "yang tidak mampu". Indonesia sebagai negara berpenduduk mayoritas muslim memiliki potensi zakat luar biasa. Bila dilihat dari capaian saat ini, raihan zakat hanya satu persen dari potensi yang ada. Keadaan ini menunjukkan bahwa lembaga zakat belum maksimal dalam mengumpulkan zakat dari muzakki.

Salah satu permasalahan yang dihadapi oleh dunia perzakatan nasional adalah tingginya kesenjangan antara potensi dengan realisasi zakat. Padahal Badan Amil Zakat Nasional (BAZNAS) secara kelembagaan juga telah memperkirakan bahwa potensi dana zakat di Indonesia bisa mencapai 100 triliun rupiah setiap tahunnya. Apabila jumlah tersebut dapat tercapai, maka berbagai program dapat dilakukan guna meningkatkan kesejahteraan masyarakat serta untuk mengurangi angka kemiskinan di Indonesia.

Namun untuk mewujudkan pemberdayaan zakat secara berkesinambungan masih terdapat kendala. Pertama, rendahnya tingkat kesadaran umat dalam menunaikan zakat. Kedua, rendahnya tingkat kepercayaan para muzakki terhadap pengelola zakat, baik yang berasal dari masyarakat maupun dari aparat pemerintah. Ketiga, masih terdapat silang pendapat diantara ulama, khususnya masalah zakat profesi.

Untuk meningkatkan jumlah penerimaan zakat, saat ini banyak lembaga zakat yang menggunakan media sebagai sarana promosi atau iklan. Disamping itu, iklan juga dapat meningkatkan kesadaran dan kepercayaan masyarakat. Bahkan lembaga zakat juga menggunakan artis sebagai bintang iklan. Pemanfaatan artis sebagai bintang iklan atau celebrity endorse oleh suatu brand untuk meningkatkan atensi dari masyarakat.

Dalam penelitian ini penyusun ingin mengetahui pengaruh celebrity endorse zakat terhadap motivasi berzakat.

\section{B. Kajian Literatur}

1. Zakat

Zakat ditinjau dari segi bahasa berasal dari kata zaqa artinya tumbuh, bersih, berkah dan baik. Sesuatu itu zaka berarti tumbuh dan berkembang, dan seseorang itu zaqa berarti orang itu baik. Menurut lisan al$a r a b$ arti dasar dari kata zakat, ditinjau dari sudut bahaa suci, tumbuh, berkah, dan terpuji, semuanya digunakan didalam alQur'an dah Hadits (Qardawi, 2001:34). Perintah zakat dijelaskan Allah dalam kalamNya, tercatat ada 82 ayat al-Qur'an yang membicarakan tentang zakat dan 
setiap ayat yang mengandung perintah zakat selalu saja terangkai dalam perintah shalat. Hal ini menunjukkan bahwa zakat sama pentingnya dengan shalat.

Sebagaimana kita ketahui, zakat terdiri dari zakat maal atau zakat harta dan zakat fitrah (Ali, 1988). Zakat maal merupakan bagian dari harta seseorang yang wajib dikeluarkan untuk mustahik. Zakat fitrah merupakan zakat yang harus ditunaikan umat Islam sebelum hari Idul Fitri di bulan Ramadhan.

2. Motivasi Berzakat

Pada dasarnya motivasi merupakan suatu proses untuk mempengaruhi agar seorang dapat atau mau melakukan sesuatu. Motivasi berasal dari bahasa latin, movere yang berarti dorongan atau daya gerak. Jadi motivasi adalah suatu perangsang keinginan dan daya penggerak kemauan bekerja seseorang, sehingga motivasi mempunyai tujuan tertentu yang ingin dicapai (Hasibuan, 1996:92).

Motivasi berzakat dalam penelitian ini diartikan sebagai kesadaran seorang untuk membayar zakat (Samdin, 2002). Hal hal yang dapat memotivasi seseorang untuk membayar zakat (Samdin, 2002):

a. Ibadah

b. Harta menjadi berkah

c. Bisnis menjadi sukses d. Dapat berbagi harta kepada orang lain. Konsep motivasi Islam tidak didasarkan pada kebutuhan yang dijelaskan, tetapi lebih kepada tingkatan hati/jiwa yang mana akan memotivasi seseorang untuk bertindak dalam sebuah sikap yang sesuai dengan Islam untuk memenuhi kepuasan hati. Penelitian yang dilakukan Lusiana Kanji, dkk (2012) menemukan ada lima faktor yang bepengaruh terhadap motivasi muzakki dalam membayar zakat, yaitu:
a. Faktor ibadah
b. Pengetahuan zakat
c. Harta kekayaan/pendapatan
d. Peran ulama, dan
e. Kredibilitas amil.

\section{Celebrity Endorse}

Menurut Mc. Cracken dalam Amos (2008) celebrity endorser adalah individu yang mendapat pengakuan oleh publik atas prestasinya dan dipercaya untuk menjadi ikon sebuah iklan. Rossiter dan Percy (1998) menyatakan bahwa celebrity endoser merupakan model iklan yang berperan besar dalam mempengaruhi audience di dalam iklan suatu produk. Jadi dapat disimpulkan celebrity endorser adalah pemanfaatan seorang publik figur yang dikenal masyarakat dan mendapat pengakuan publik atas prestasinya dan dipercaya menjadi icon sebuah iklan 
sehingga dapat mendukung produk yang dipromosikannya.

Menurut Kotler (1997) pemilihan tokoh dalam menyampaikan pesan merupakan faktor yang sangat penting, tokoh tersebut harus dikenal luas, mempunyai pengaruh positif yaitu efek emosi yang positif terhadap audien dan sesuai dengan produk yang dibintanginya.

Rossiter dan Percy (1998) berpendapat terdapat empat karakter yang harus dimiliki celebrity endorser, yakni:

a. Visibility (Kepopuleran)

b. Credibility (Kredibilitas)

c. Attractiveness (Daya Tarik)

d. Power (Kekuatan)

Menurut Schiffman dan Kanuk peran celebrity endorser yang bias digunakan perusahaan dalam sebuaha iklan (dalam Mahestu Noviandra, 2006):

a. Testimonial, artis akan memberikan kesaksian mengenai produk.

b. Endorsement, artis akan mengiklankan produk tersebut.

c. Actor, artis menjadi bintang iklan dalam promosi produk.

d. Spokeperson, artis menjadi juru bicara produk tersebut dihadapan publik.

\section{Metode Penelitian}

Penelitian ini adalah penelitian kuantitatif, yakni penelitian yang melihat hubungan variabel terhadap objek yang diteliti bersifat sebab-akibat (kausal), sehingga dalam penelitiannya ada variabel independen dan dependen. Data yang di gunakan adalah data primer, dimana teknik pengumpulan data menggunakan angket atau kuesioner.

Dalam penelitian ini yang menjadi populasi adalah masyarakat Yogyakarta. Teknik pengambilan sampel yang di gunakan dalam penelitian ini adalah convience sampling.

Instrumen dalam penelitian ini, antara lain:

\begin{tabular}{|l|l|c|}
\hline \multicolumn{1}{|c|}{ Variabel } & \multicolumn{1}{c|}{ Indikator } & Item \\
\hline Motivasi Zakat & Ibadah & $1-3$ \\
(Samdin, & Harta berkah & $4-5$ \\
2002) & - Bisnis sukses & $6-7$ \\
& - Berbagi harta & $8-9$ \\
\hline Kriteria & Visibility & $10-11$ \\
Endorser & - Credibility & $12-15$ \\
(Rossiter dan & Attractiveness & $16-20$ \\
Percy 1998) & Power & $21-23$ \\
\hline
\end{tabular}

Sumber: diolah (2015)

Setiap alternatif jawaban dari variabel akan diberi skor, dalam pemberian skor penulis menggunakan skala likert, sebagai berikut:

\begin{tabular}{|l|c|}
\hline \multicolumn{1}{|c|}{ Alternatif Jawaban } & Skor \\
\hline Sangat Setuju (SS) & 4 \\
Setuju (S) & 3 \\
Tidak Setuju (TS) & 2 \\
Sangat Tidak Setuju (STS) & 1 \\
\hline
\end{tabular}

Sumber: diolah (2015)

Metode analisis yang digunakan untuk tujuan mengetahui pengaruh celebrity endorse zakat terhadap motivasi berzakat adalah dengan menggunakan analisis regresi sederhana. Model hubungan kinerja dengan varibelvariabel tersebut dapat disusun dalam fungsi atau persamaan sebagai berikut:

$\hat{\mathrm{Y}}=\mathrm{b}_{0}+\mathrm{b}_{1} \cdot \mathrm{X}$ 
Keterangan:

$\mathrm{Y} \quad=$ Motivasi berzakat

$\mathrm{b}_{0} \quad=$ Konstanta

$\mathrm{X}=$ Celebrity Endorser

$\mathrm{b}_{1} \quad=$ Koefisien Regresi

\section{Hasil dan Pembahasan}

Setelah dilakukan perhitungan dengan menggunakan program SPSS diperoleh hasil sebagai berikut:

\begin{tabular}{|c|c|c|c|c|}
\hline Variabel & $\begin{array}{c}\text { Koefisien } \\
\text { Regresi }\end{array}$ & $\begin{array}{c}\text { Standard } \\
\text { Error }\end{array}$ & $\stackrel{\mathrm{t}}{\mathrm{h}}$ & Sig. $\mathrm{t}$ \\
\hline$X$ & 0,258 & 0,061 & 2,648 & 0,009 \\
\hline Konstanta & 21,625 & & & \\
\hline $\mathrm{R}$ & 0,258 & & & \\
\hline R Square & 0,067 & & & \\
\hline $\mathrm{F}$ & 7,012 & & & \\
\hline Sig. F & 0,009 & & & \\
\hline
\end{tabular}

Sumber: diolah (2015)

Berdasarkan hasil analisis regresi sederhana di atas, maka dapat disimpulkan beberapa temuan, diantaranya:

1. Konstanta $\left(\mathrm{b}_{0}\right)=21,625$

Artinya apabila variabel celebrity endorse tidak ada atau sama dengan nol maka motivasi berzakat memiliki nilai positif sebesar 21,625

2. Koefisien regresi $\left(b_{1}\right)=0,258$

Artinya apabila motivasi berzakat yang berhubungan dengan celebrity endorse lebih baik, maka motivasi berzakat akan naik sebesar 0,258 dengan asumsi variabel lain tetap.

3. Sig. $\mathrm{t}=0,009$

Diketahui nilai t-hitung sebesar 2,648 dengan sig. $\mathrm{t}$ sebesar $0,009(\mathrm{p}<0,05)$, sehingga keputusannya menolak Ho dan menerima Ha. Berarti ada pengaruh yang signifikan dan positif antara variable celebrity endorser terhadap motivasi berzakat.

4. Koefisien Determinasi $\left(\mathrm{R}^{2}\right)=0,067$

Artinya kontribusi varian yang diberikan oleh variabel celebrity endorser terhadap motivasi berzakat adalah sebesar 6,7\%, sedangkan sisanya, yakni sebesar 93,3\% dipengaruhi oleh varian lain di luar model. Berdasarkan menunjukkan bahwa variabel celebrity endorser memiliki pengaruh yang signifikan dan positif terhadap motivasi berzakat, dengan tingkat signifikansi sebesar 0,009. Disamping itu ditemukan kontribusi variabel celebrity endorser terhadap motivasi berzakat sebesar 0,067, artinya kontribusi varian yang diberikan adalah sebesar $6,7 \%$, adapun sisanya sebesar 93,3\% dipengaruhi oleh varian lain diluar model penelitian.

Temuan ini menunjukkan dua kemungkinan, Pertama, celebrity endorser yang digunakan oleh LAZ, dalam hal ini Dompet Dhuafa kurang kuat dalam menarik minat masyarakat sehingga masyarakat tidak termotivasi setiap melihat, mendengar, ataupun memperhatikan celebrity endorser dari LAZ. Kedua, motif berzakat dari masyarakat lebih dominan berasal dari faktor internal bukan dari faktor eksternal. Sehingga ajakan atau himbauan 
dari artis tidak memberikan pengaruh yang terlalu besar bagi para muzakki.

Berangkat dari hal tersebut, maka bagi LAZ khususnya bagian divisi funding, untuk lebih memperhatikan faktor-faktor yang memiliki dampak lebih besar dalam memotivasi masyarakat untuk berzakat. Hal ini juga terkait dengan efisiensi LAZ. Dimana dana untuk beriklan tidak terbuang sia-sia tanpa menghasilkan dampak yang signifikan. Berangkat dari hal tersebut diperlukan kreativitas dan usaha yang lebih untuk menarik minat dan memotivasi masyarakat dalam berzakat.

\section{E. Penutup}

1. Kesimpulan

Variabel celebrity endorser berpengaruh positif dan signifikan terhadap motivasi berzakat. Hal ini dilihat dari nilai t hitung sebesar 2,648 dengan sig. t sebesar 0,009 $(\mathrm{p}<0,05)$. Kontribusi variabel celebrity endorser terhadap motivasi berzakat sebesar 0,067 yang berarti kontribusi varian yang diberikan oleh variabel celebrity endorser terhadap motivasi berzakat adalah sebesar $6,7 \%$.

2. Saran

Diperlukan kreativitas dan usaha yang lebih bagi LAZ dalam menarik minat dan memotivasi masyarakat, selain karena hanya dengan menggunakan bantuan artis saja terbukti tidak memberikan dampak yang besar.

\section{F. Daftar Pustaka}

Ali, Muhammad Daud. 1988. Sistem Ekonomi Islam: Zakat dan Wakaf. Jakarta: UI Press.

Amos, N. 2008. Kesadaran Lingkungan. Jakarta: Rineka Cipta.

Hasibuan, Malayu S. P. 1996. Manajemen Dasar, Pengertian dan Masalah. Jakarta: PT. Gunung Agung.

Karim, Adiwarman. 2004. Sejarah Pemikiran Ekonomi Islam. Jakarta: Raja Grafindo Persada.

Kotler, Philip. 1997. Manajemen Pemasaran, Analisis, Perencanaan, Implementasi dan Kontrol (Jilid 1). Jakarta : Prehalindo.

Mc Cracken, G. 1989. "Who Is The Celebrity Endorser? Cultural Foundations Of The Endorsement Process," Journal Of Consumer Research, Vol 16, No 3, pp.310-321.

Qardhawi, Yusuf. 2001. Hukum Zakat (terjemahan dari buku Fiqhuz Zakat). Jakarta: Pustaka Litera AntarNusa.

Rossiter, John R, dan Larry Percy. 1998. Advertising Communication and Promotion Management. Edisi Kedua, Singapura; McGraw-Hill.

Schiffman, Leon G. dan Leslie Lazar Kanuk. 2004. Consumer Behavior. Seventh Edition. New Jersey: Prentice Hall,Inc. 